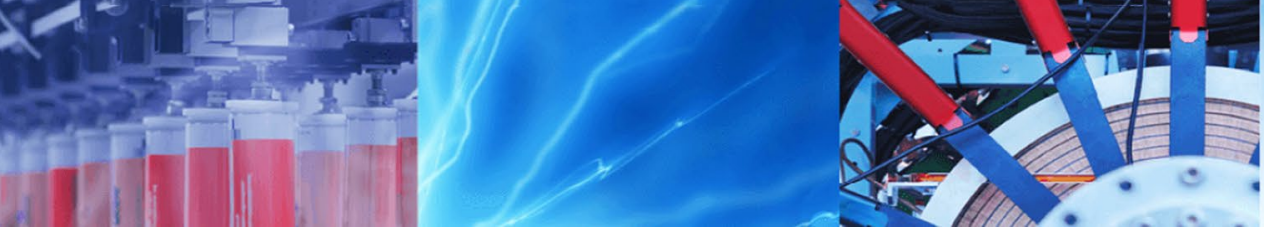

Research Article

\title{
Assessing blasting techniques in vibration sensitive areas at Kinross - Round Mountain to enhance blasting criteria
}

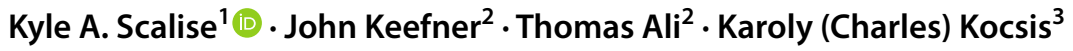

Received: 19 May 2020 / Accepted: 20 November 2020 / Published online: 2 December 2020

(c) Springer Nature Switzerland AG 2020

\begin{abstract}
This study presents an improved methodology for selecting blasting criteria at open pit mines through the incorporation of radar data. This study compiles a combination of geophone data, which obtain peak particle velocity and dominant frequency of ground motions, radar, which observe slope velocity and current blasting practices to improve upon the blasting criteria present at Round Mountain. The combination of data sources showed that while peak particle velocity is important when analyzing blasting performance, radar response and dominant frequency assist with obtaining a more detailed understanding. Additionally, the comparison of modified production blasts to trim blasts showed that the application of trim blasts in vibration sensitive areas is preferable. The importance of incorporating radar data into the blast design criteria is significant because radar measures movement of the highwall while geophones only measure the motion of the ground in response to a blast. Improved blasting criteria allow for a more precise and consistent blasting performance, which, in turn, creates a safer geotechnical environment leading to less downtime and more cost savings.
\end{abstract}

Keywords Blast vibration · Geotechnical engineering $\cdot$ Mining $\cdot$ Peak particle velocity (PPV) $\cdot$ Frequency $\cdot$ Wall control blasting $\cdot$ Radar

\section{Introduction}

Monitoring open pit mine blasting vibrations is necessary to understand the impact that blasts have on the highwall. Assessing the performance of a mine blast from a geotechnical perspective typically requires analyzing ground motions, performing visual inspections and utilizing site-specific criteria, such as peak particle velocity and dominant frequency, to rank the quality of the blast. Blast vibration data and radar are used at most open pit mines. However, a blasting criteria incorporating radar velocity is uncommon. This study compiles a combination of geophone data, which obtain peak particle velocity and dominant frequency of ground motions, radar, which observe slope velocity and current blasting practices to improve upon the blasting criteria present at Round Mountain.
The importance of incorporating the radar into the blast design criteria is that the radar measures movement of the highwall. In addition to improved blasting criteria, a comparative assessment of trim blasting vs. modified production blasting is completed to better understand the ideal wall control technique to be used at sensitive mining locations.

Blast vibration monitoring is crucial for understanding backbreak as well as the effect on slope stability [1]. Improper blasting can create damaging ground vibrations that can displace rocks and encourage slope failure [1]. Therefore, a proper blast monitoring plan must be implemented at every active open pit mine. Blast vibration monitoring allows for changes to be made to a mine's blasting practice to minimize harmful vibrations that cause damage to the highwall and result in mine safety hazards.

Kyle A. Scalise, kscalise@nevada.unr.edu| ${ }^{1}$ University of Nevada, Reno, NV, United States. ${ }^{2}$ Kinross - Round Mountain Gold Corporation, Round Mountain, NV, United States. ${ }^{3}$ Mining and Metallurgical Engineering Dôepartment, University of Nevada, Reno, NV, United States. 
Without a blast monitoring program, it is difficult to assess the success or ineffectiveness of a blast. At Round Mountain, the monitoring plan includes constant radar observation, geophone placement before blasting, pre-blast and post-blast inspections and assessment of geophones and radar post-blast. However, the criteria used does not include a combination of all monitoring systems. The more parameters that can be included in a blast vibration monitoring program, the safer and more productive the mine will become.

\subsection{Round Mountain blast criteria}

The main blasting criteria used at Round Mountain to analyze ground motion from geophones uses peak particle velocity (PPV) and dominant frequency. The acceptable ranges used for these criteria are based on the experience of geotechnical engineers, blasting consultants and guidelines set within the Round Mountain blasting program. The criteria used have been successful, but areas sensitive to vibrations remain a concern. Therefore, the criteria have the opportunity for improvement through analyzing a compilation of sources. Recent work completed by Orica [2] along with geophone and radar data, will be integrated to improve upon the current blasting program at Round Mountain, especially in areas with blast sensitivity.

The majority of traditional blasting criteria involve the assessment of PPV [3-7] with some incorporating dominant frequency [3]. A major factor of PPV usage in blast vibration criteria is its convenience of measurement and ease of assessment [4]. PPV is still used extensively to determine blast performance even though it only accounts for particle movement and not highwall movement. Many times, studies involving blasting vibration effects normally relate to the effects of the blast vibrations on infrastructure such as roadways [5], not necessarily the effect blasting has on the mine highwall.

\subsection{Ground-based radar}

Ground-based radar is able to detect movement with high accuracy [6] and is used in a variety of slope stability applications, including bridges and landslides [7], volcanoes [8], natural and engineered slopes [9] and mining applications [10]. The majority of mining applications in the literature involve discussions of radar for overall slope monitoring [6] and the applications for analyzing blasting with radar are scarce. Rajmeny and Shrimali [4] discuss using radar but for the purpose of monitoring movement along faults not for monitoring highwall movement post-blast. Saunders et al. [11] discusses radar assessment post-blast, but not in vibration sensitive areas or in conjunction with other assessments. Therefore, there is an opportunity to expand knowledge for the application of radar for blast vibration monitoring. Another radar technology that is worth mentioning but not discussed within this paper is InSAR (Interferometric Synthetic Aperture Radar). InSAR is a satellitebased radar that has slope stability applications within the geosciences [12] and the mining industry [13].

\subsection{Wall control blasting techniques}

Trim (cushion) blasting and modified production blasting are wall control blasting techniques used in locations that are sensitive to ground vibration [1]. Wall control blasting techniques are designed to direct energy away from the highwall. Generally, trim blasting is typically used for rock that is too weak for modified production blasting [1] and divides a blast pattern into separate blasting events, as seen in Fig. 1. The trim blast is typically shot after the main production blast and after the face has been cleaned to less than a burden-distance to minimize vibrations directed into the highwall. The advantage of using a trim blast is that there is a fully relieved face that allows rows of material to move away, preventing recoil energy from damaging the final wall. When comparing the trim vs. the modified production blasting ground vibrations, the production blasts are shown separately even though they are the initial phase of trim blasting. Modified production blasting reduces the overall energy of the blast pattern, typically by reducing charge weights near the highwall by thirty to sixty percent, and is used on more competent rock masses when compared to trim blasting [1]. An example of a modified production blast pattern can be seen in Fig. 2.

Both blasting techniques mentioned are used at Round Mountain. There are debates as to which blasting technique creates less vibration and is less impactful to sensitive highwall areas [14]. Like many blasting practices, the choices that determine blast design and which techniques work are very site-specific. Figures 1 and 2 are representative of the blast patterns that are assessed within this paper because they are the patterns that are used at Round Mountain. The blast timing is $33 \mathrm{~ms}$ for the burden and $63 \mathrm{~ms}$ for the spacing. The blasting agent used is an emulsion and the number of blast holes in these sensitive locations can be up to 300 holes. Typical hole diameters and bench height would be 6.75 inches and 35 feet, respectively. The blast pattern design and location of drill holes would change depending upon the location and orientation within the open pit, but the figures help define the major characteristics for both wall control methods. Trim blasts are smaller patterns shot near the highwall, while modified production blast patterns can be loaded with less explosive near the highwall. The goal for both methods is to reduce damage to the highwall, but their 


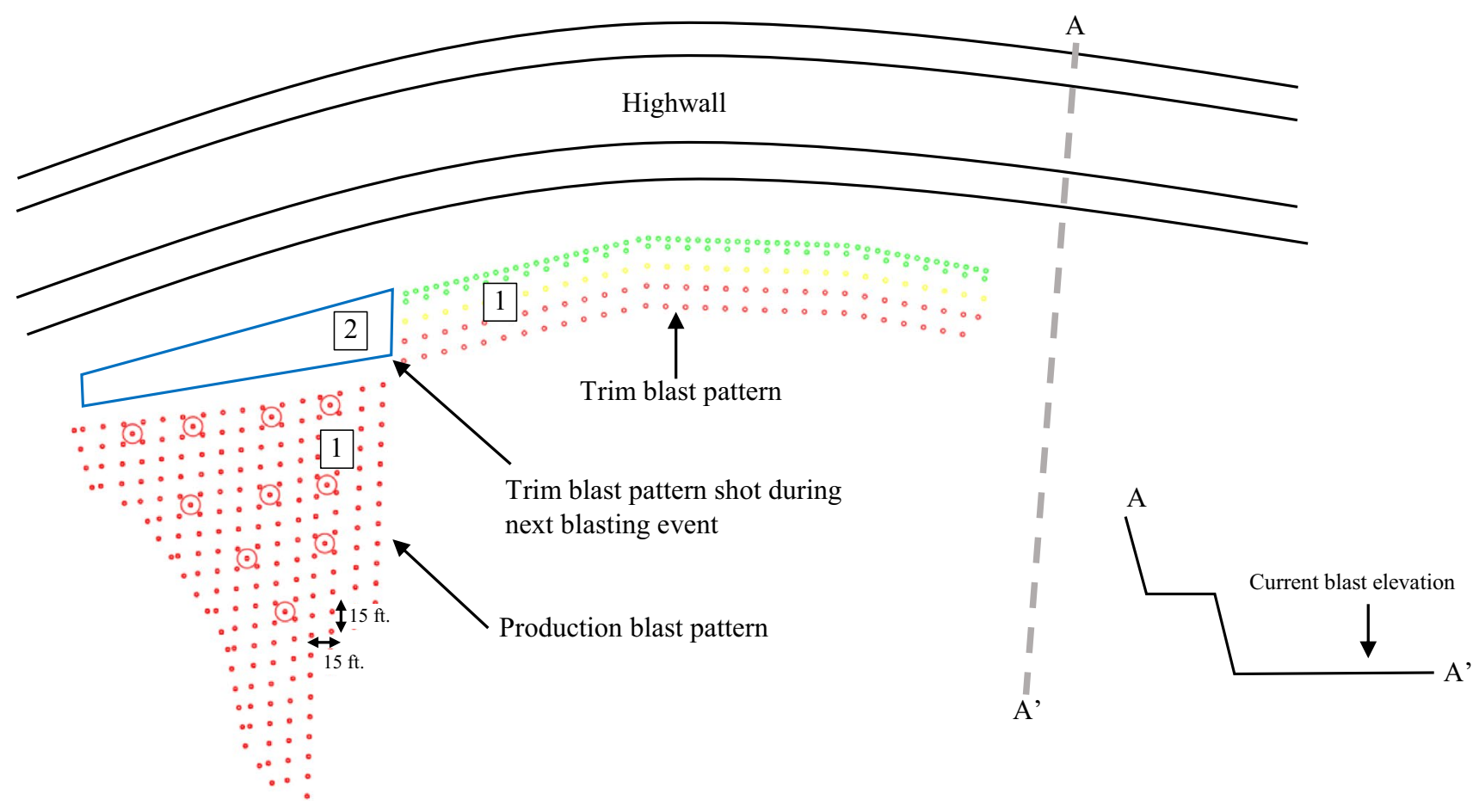

Fig. 1 Trim Blast Pattern with production shot (plan view). The trim pattern and production pattern shown would be shot as one blasting event labeled as " 1 ". The blast holes with green are the trim blast holes that are shot freefaced next to the highwall to minimize highwall impact in sensitive locations. The pattern on the left with all red blast holes shows holes that would be shot before the next trim shot to open up a freeface. The next trim shot, labeled as " 2 ",

designs differ. To understand if trim blasting or modified production blasting is less impactful on the mine highwall at Round Mountain, a comparison between the radar velocity, PPV and dominant frequency observed on the geophones is completed. The PPV detected by the geophone corresponds to ground motion while the velocity detected by the radar shows the movement of the highwall specifically measured at a location with earlier rockfall events, the New North Wall Failure (NNWF) area. This location is above the events that are measured with the geophones. Eighteen radar pixels are selected to analyze the average velocity post-blast to compare to the geophone data as well as the blasting criteria.

\section{Methods}

\subsection{Location and geology}

Round Mountain is located in Nye County, Nevada, United States; 97 km [60 miles] north of Tonopah, Nevada. Round Mountain is an open pit gold mine with 385,601 oz of gold equivalent production in the year 2018 [15]. In 2018, that would be shot the next time the area is blasted, would be right above the all-red production blast shown with the blue polygon. This location is shot after both the blast patterns labeled "1" have been dug out to to open up a free face for the next trim shot. The A-A' line through the schematic shows a section view of the highwall and the elevation of the current blast pattern

Kinross also poured its 15 millionth ounce of gold [15]. The Round Mountain Gold deposit is an epithermal, low-sulfidation, volcanic-hosted, hot springs type, precious metal deposit, interpreted to follow the margin of a buried volcanic caldera - the Round Mountain Caldera [16]. Caldera collapse features and faulting in the metasedimentary rocks provided the major structural conduits for gold-bearing hydrothermal fluids where these ascending fluids deposited gold along a broad west-northwest trend [16]. The rock type that is analyzed throughout this study are Paleozoic metasediments basement rock that are deformed and variably metamorphosed as quartzites, argillites and limestones of the Mayflower Schist, the Gold Hill Formation, and the Zanzibar Limestone, which exhibits abundant fracture-controlled mineralization [17]. It is important to note that the bedding of Type 4 is a key controlling factor in blasting and wall control. Type 4 has an RQD of $85 \%$ from core logging, an RMR of 61 , a rock quality designation of "good", a density of $160 \mathrm{lbs} / \mathrm{ft}^{3}$, and an intact friction and cohesion of 50 degrees and $430 \mathrm{psi}$, respectively.Type 4 is located in the bottom of the pit as well as a large portion of the eastern wall - all rock types 


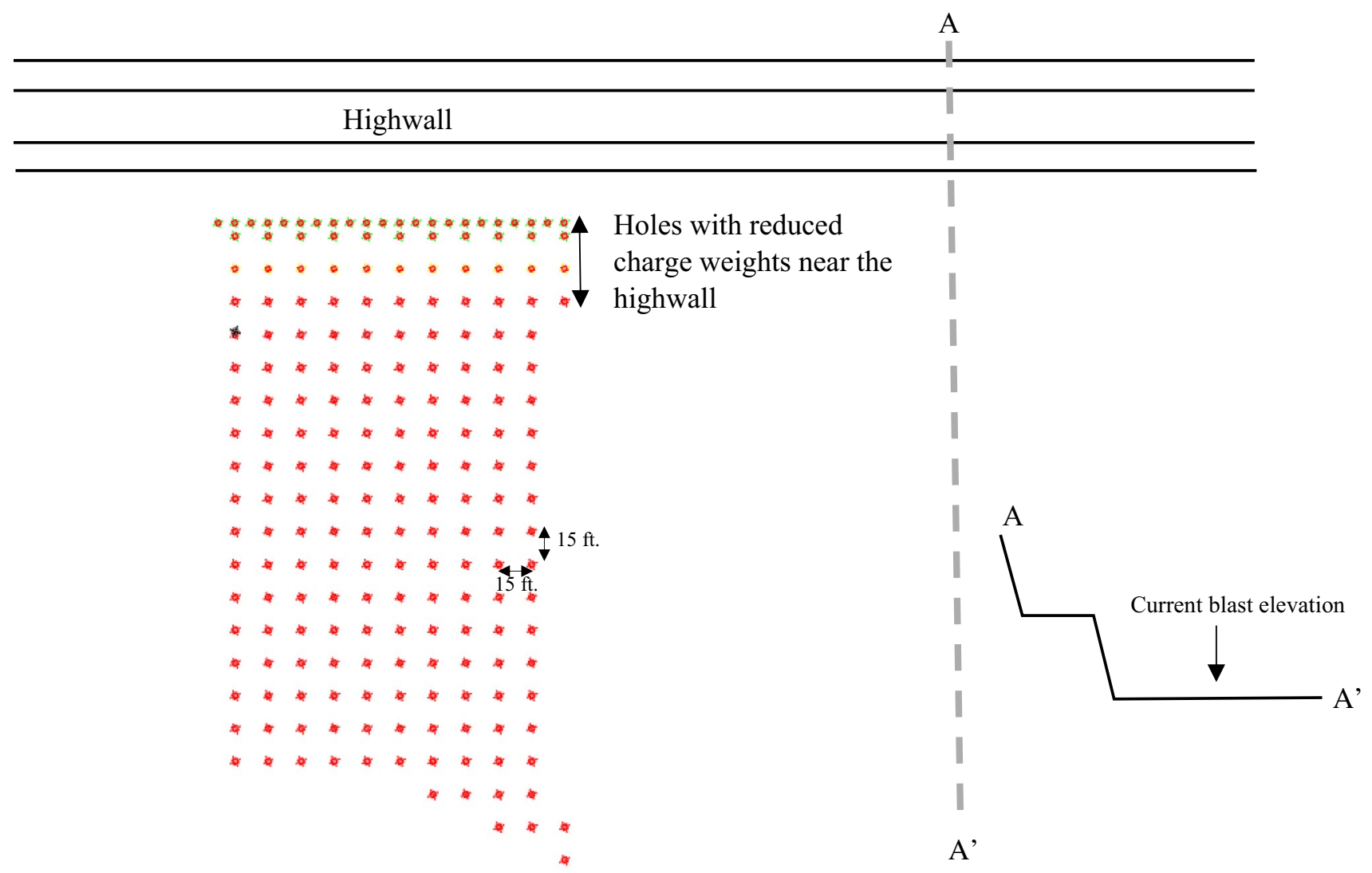

Fig. 2 Modified Production Blast Pattern (plan view). The modified production blast pattern can be see by the group of drill holes shown. The modified production blasts discussed within this paper are "modified" because the charge weight of explosives is reduced

dip toward the west due to large amounts of faulting that run north-south along the range front in this location.

\subsection{Equipment and data collection}

\subsubsection{Seismograph}

To measure ground vibrations, a Mini-Seis ${ }^{\mathrm{TM}}$ Seismograph from White Industrial Seismology, Inc. is used. The MiniSeis ${ }^{\mathrm{TM}}$ seismic sensor contains a three-component velocity geophone with radial, vertical and transverse components [18]. The sampling rate used is 1024 samples per second. To analyze the data from the geophone, the Seismograph Data Analysis program from White Industrial Seismology, Inc. is utilized. This program allows the user to view the waveforms as well as determine the dominant frequency of the blast event using a Fast Fourier Transform (FFT) [19]. Telgarsky [20] describes the dominant frequency as the frequency that carries the maximum energy among all frequencies found in the spectrum, which is important to understand because this frequency has the highest near the highwall to minimize highwall damage. The $A-A^{\prime}$ line through the schematic shows a section view of the highwall and the elevation of the current blast pattern

potential to damage the highwall. The goal of a mine blast is to shift the dominant frequency outside the fundamental or natural frequency of the rock called frequency shifting, while also keeping the PPV's low [21].

To collect reliable data, two seismographs should be placed - a near-field (NF) and a far-field (FF). The NF should be located 200 feet away (up to 250 feet away is acceptable) from the last blast hole in the pattern. The FF should be 400 feet or greater from the last blast hole. The goal is to place the geophone arrow in line with the Point of Initiation (POI) and the last blast hole.

\subsubsection{Radar monitoring}

The radar that monitors the NNWF area is a Reutech MSR Radar. The Reutech radar is a real aperture, groundbased radar with the ability to perform survey scans over large areas in a short period of time, obtaining data from transmitting and receiving electromagnetic waves [22]. It measures velocity using interferometric methods and reports data with a user-friendly interface [23]. To better 
understand the highwall movement of our blasts, the average velocity of 18 points located on the NNWF area will be analyzed. The MSR has a computer interface that allows the user to select points of concern. The MSR then shows the velocity of movement occurring on the selected points. Several points are selected because a single individual point is not representative of the movement of the slope. For example, if a rock moved, this might show extremely high velocity though the slope may be relatively unaffected.

\subsection{Current blast vibration criteria}

The current blast criteria used at Round Mountain involves a PPV and frequency assessment that can be seen in Fig. 3. Green represents ideal values, yellow represents values that should be improved, and red values indicate values that are of major concern from a ground vibration perspective.

Therefore, based on the criteria shown in Fig. 3, an ideal blast would have a PPV between 0-1 inches per second (ips) and a frequency above $20 \mathrm{~Hz}$. In addition, Round Mountain performs pre-blast and post-blast inspections.

\subsection{Velocity attenuation curve and scaled distance}

Velocity attenuation curves are graphs of scaled distance vs. PPV and give site-specific equations for PPV. In addition to site-specific equations, it helps understand how PPV varies as a function of distance from the blast as well as how PPV varies as a function of charge weight. Scaled distance can be seen in Eq. 1, below.

$S D=\frac{\text { Distance from blast }}{\sqrt{\text { Charge Weight }}}$

For the purposes within this study, a site-specific equation is not calculated because the data selected is not complete for Type 4 rock, though this is possible if all blast data were included. The data selected is located in areas close to highwalls that require wall control blasting. The velocity attenuation curve will be used to flag PPV's that do not fall within the current blast criteria.

\section{Results}

\subsection{Geophone results}

The results of the seismograph readings along with some additional blasting data, such as scaled distance and charge weight, can be seen in Table 1. The date and time for each blast is shown with time being important when comparing the vibration data to the radar. The reason for the duplication of dates in the table is due to the recording of both near and far-field.

The 'Blast Type' and 'Blast Pattern ID' are also shown in Table 1 . The blasts on $7 / 15 / 19$ are modified production (MP) blasts. The blasts on 7/19/19-7/22/19 are production blasts, not modified, meaning there is no reduction in charge weight. Again, a production blast is part of the trim blast pattern but occurs before the trim shot. For comparison purposes, the production shot is analyzed separately for ground vibrations, but it is considered as part of the trim shot. On $7 / 24 / 19$, the blast includes the trim shots from the previous two production shots on the dates $7 / 19 / 19$ and $7 / 22 / 19$ as well as the production blast for $7 / 24 / 19$. On $7 / 29 / 19$, this is only the trim blast or the remaining holes from the previous day. Finally, on 7/31/19, a production blast occurs. The distance values shown are the slope distances measured from the last blast hole to the seismograph.

The results of PPV and frequency are color-coded to match the current blast criteria mentioned above (see Fig. 3) and the bold values show the max PPV. Radial, vertical and transverse components are abbreviated as $\mathrm{R}, \mathrm{V}$ and $T$, respectively. The average dominant frequency is the average of the three components. This parameter will be used to assess the overall blast from a frequency perspective. While the individual components are important, an average gives a more concise overall picture of the vibrations affecting the highwall. Additionally, events that are concerning (yellow and red) are still flagged as concerning after averaging.

The maximum PPV and scaled distance are used to plot the velocity attenuation curve for our selected events. BXS is the burden and spacing for each event. The charge weight is the amount of blasting product used in pounds. Finally, the scaled distance is shown and calculated with Eq. 1 above.

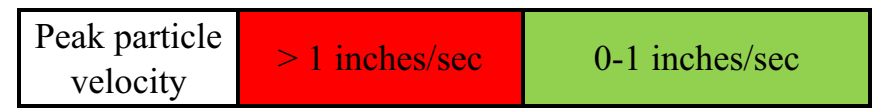

Fig. 3 Current blast vibration criteria

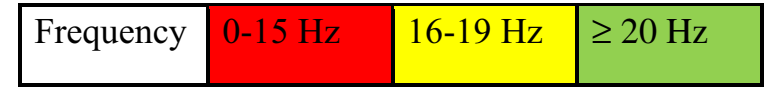




\subsection{Radar results}

Figure $5 a-f$ displays the radar images corresponding to the dates listed in Table 1 with time and date on the $x$-axis and average velocity (inches/hour) on the $y$-axis. Negative velocities indicate the slope moving away from the radar, while positive velocities represent the slope moving toward the radar. The red line indicates when the blast occurred. The magnitude of the line to the right of the radar images shows the average velocity of slope movement initiated by blasting and the color-coding of each line is a criterion developed to quantify each radar event. To develop the radar criteria, the average velocity magnitude of each pixel was determined as shown by the value next to the line to the right of Figs. 5a-f. Each event was assessed individually to determine how extreme each slope movement seemed when compared to another. The events that were the most extreme (Fig. 5a) were given red color-coding, events that seemed impacted by blasting but less extreme (Figs. 5b, d, e) were given yellow color coding and events that did not seem very impacted by blasting (Figs. 5c, e) were given green color coding. From these results, criteria values were determined empirically. Figure 4 shows the blasting criteria determined from the radar data.

Figure 5a shows significant slope movement from the MP blast occurring on 7/15/19, while the blast criteria do not show any red flags in Table 1 . This is a significant discrepancy as there should be an indication of red flags occurring in Table 1 because the slope felt a significant \begin{tabular}{|l|l|l|} 
Radar Ave. Vel. (in/h) & $<0.005$ & $0.005-0.015$ \\
\hline
\end{tabular}

Fig. 4 Radar criteria

effect from the blast. Also, the effect of the MP blast is very extreme for an area with blast sensitivity. Figure $5 \mathrm{~b}$ shows a slight downward (negative) velocity trend, again with no red flags showing up in Table 1 and this is another MP blast. Figure $5 c(7 / 22 / 19)$ shows little indication of any trends occurring because of blasting. This event has the least movement $(0.002 \mathrm{in} / \mathrm{h})$ when compared to the other events. The interesting result on day $7 / 22 / 19$ is that there is a red flag occurring in Table 1 for the PPV in the radial direction for the NF geophone. This is expected because this is the production shot (no reduction in charge weight) preceding the trim blast that will occur on $7 / 24 / 19$. This would indicate that though the PPV is high, though it does not translate into energy entering the highwall and causing any slope movement. Additionally, this supports the principle that waiting to shoot the trim blast holes next to the highwall does alleviate vibration impacting the slope. This also indicates that PPV is less impactful to the highwall than improper frequency ranges and that additional leniency may be added to the new criteria if the dominant frequency falls within an acceptable range.

Figure $5 \mathrm{~d}$ indicates movement initiated by blasting. There are red and yellow flags present for the frequency and PPV readings in Table 1 as well. The NF PPV reading of 1.24 is red, but is relatively close to 1 , which is not overly

Table 1 Seismograph results and blasting data

\begin{tabular}{|c|c|c|c|c|c|c|c|c|c|c|c|c|c|c|}
\hline \multirow[b]{2}{*}{ Date } & \multirow[b]{2}{*}{ Time } & \multirow[b]{2}{*}{$\begin{array}{l}\text { Blast } \\
\text { Type }\end{array}$} & \multirow[b]{2}{*}{$\begin{array}{c}\text { Blast } \\
\text { Pattern } \\
\text { ID }\end{array}$} & \multirow[b]{2}{*}{$\begin{array}{c}\text { Distance } \\
\text { (feet) }\end{array}$} & \multicolumn{3}{|c|}{ PPV (in/s) } & \multicolumn{3}{|c|}{ Frequency (Hz) } & \multirow[b]{2}{*}{$\begin{array}{c}\text { Average } \\
\text { Dominant } \\
\text { Frequency }\end{array}$} & \multirow[b]{2}{*}{$\begin{array}{c}\text { BxS } \\
\text { (ftxft) }\end{array}$} & \multirow[b]{2}{*}{$\begin{array}{c}\text { Charge } \\
\text { Weight } \\
\text { (lbs) }\end{array}$} & \multirow[b]{2}{*}{$\begin{array}{c}\text { Scaled } \\
\text { Distance }\end{array}$} \\
\hline & & & & & $\mathbf{R}$ & $\mathbf{V}$ & $\mathbf{T}$ & $\mathbf{R}$ & $\mathbf{V}$ & $\mathbf{T}$ & & & & \\
\hline $7 / 15 / 2019$ & $\begin{array}{c}2: 47 \\
\text { PM }\end{array}$ & MP & 1 & 239 & 1.00 & 0.79 & 0.84 & 32.5 & 32.0 & 32.0 & 32.2 & $15 \times 15$ & 606 & 10 \\
\hline $7 / 15 / 2019$ & $\begin{array}{c}2: 47 \\
\text { PM }\end{array}$ & MP & 1 & 413 & 0.74 & 0.47 & 0.44 & 31.8 & 32.5 & 33.3 & 32.5 & $15 \times 15$ & 606 & 17 \\
\hline $7 / 19 / 2019$ & $\begin{array}{l}5: 48 \\
\text { AM }\end{array}$ & $\mathrm{P}$ & 2 & 240 & 0.59 & 0.86 & 0.69 & 32.0 & 32.5 & 33.5 & 32.7 & $15 \times 15$ & 642 & 9 \\
\hline $7 / 19 / 2019$ & $\begin{array}{l}5: 48 \\
\text { AM } \\
\end{array}$ & $\mathrm{P}$ & 2 & 363 & 0.32 & 0.47 & 0.39 & 32.3 & 32.3 & 32.3 & 32.3 & $15 \times 15$ & 642 & 14 \\
\hline $7 / 22 / 2019$ & $\begin{array}{l}2: 25 \\
\text { PM }\end{array}$ & $\mathrm{P}$ & 3 & 192 & 5.70 & 1.48 & 0.76 & 31.3 & 32.0 & 32.8 & 32.0 & $15 \times 15$ & 678 & 7 \\
\hline $7 / 22 / 2019$ & $\begin{array}{l}2: 25 \\
\text { PM }\end{array}$ & $\mathrm{P}$ & 3 & 282 & 0.42 & 0.49 & 0.25 & 31.8 & 32.0 & 32.5 & 32.1 & $15 \times 15$ & 678 & 11 \\
\hline $7 / 24 / 2019$ & $\begin{array}{c}3: 03 \\
\text { PM }\end{array}$ & $\mathrm{T} / \mathrm{P}$ & $2-3 \mathrm{~T} / 4$ & 192 & 1.24 & 0.83 & 0.72 & 29.3 & 30.3 & 31.5 & 30.3 & $15 \times 15$ & 642 & 8 \\
\hline $7 / 24 / 2019$ & $\begin{array}{l}3: 03 \\
\text { PM }\end{array}$ & $\mathrm{T} / \mathrm{P}$ & $2-3 \mathrm{~T} / 4$ & 387 & 0.30 & 0.28 & 0.33 & 18.8 & 12.0 & 16.3 & 15.7 & $15 \times 15$ & 642 & 15 \\
\hline $7 / 29 / 2019$ & $\begin{array}{l}2: 33 \\
\text { PM }\end{array}$ & $\mathrm{T}$ & 4 & 208 & 0.62 & 0.35 & 0.42 & 30.0 & 30.0 & 31.5 & 30.5 & $15 \times 15$ & 642 & 8 \\
\hline $7 / 29 / 2019$ & $\begin{array}{c}2: 33 \\
\text { PM }\end{array}$ & $\mathrm{T}$ & 4 & 468 & 0.21 & 0.18 & 0.16 & 29.5 & 30.0 & 31.5 & 30.3 & $15 \times 15$ & 642 & 18 \\
\hline $7 / 31 / 2019$ & $\begin{array}{l}2: 19 \\
\text { PM }\end{array}$ & $\mathrm{P}$ & 5 & 246 & 0.59 & 0.63 & 0.51 & 32.3 & 32.3 & 32.5 & 32.3 & $15 \times 15$ & 552 & 10 \\
\hline $7 / 31 / 2019$ & $\begin{array}{l}2: 19 \\
\text { PM }\end{array}$ & $\mathrm{P}$ & 5 & 466 & 0.18 & 0.30 & 0.15 & 16.3 & 10.0 & 32.0 & 19.4 & $15 \times 15$ & 552 & 20 \\
\hline
\end{tabular}




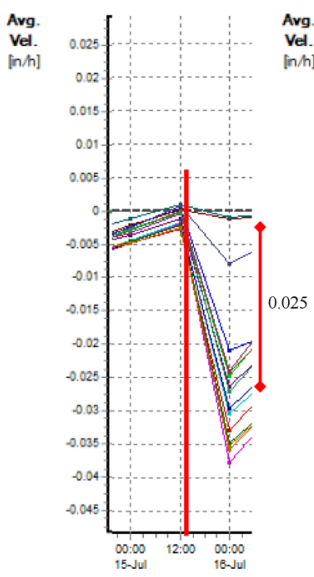

a

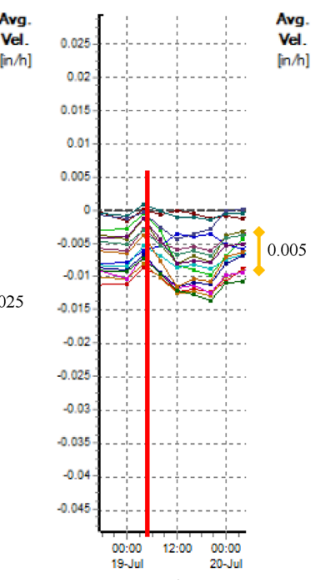

b

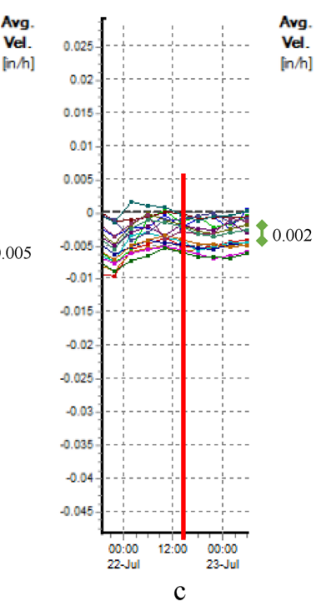

C

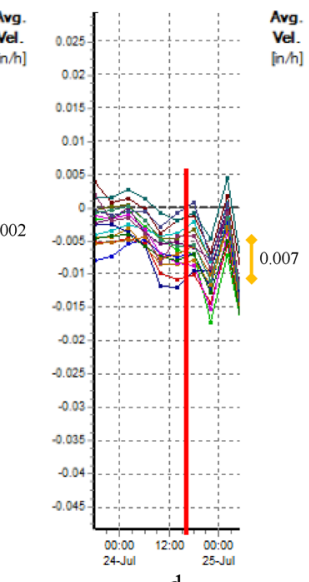

d

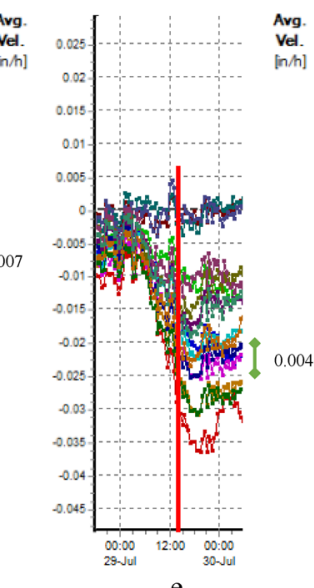

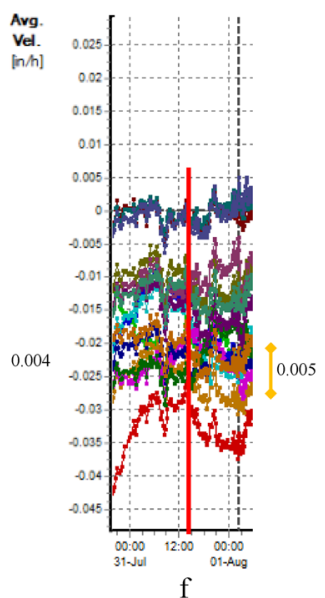

f
Fig. 5 Radar Average Velocity. Dates for inset image: a $7 / 15 / 19, \mathbf{b}$ $7 / 19 / 19$, c $7 / 22 / 19$, d 7/24/19, e $7 / 29 / 19$, f 7/31/19. Red line shows when the blast occurred. The events that were the most extreme (Fig. 5a) were given red color-coding, events that seemed impacted by blasting but less extreme (Fig. 5b, d, e) were given yellow color coding and events that did not seem very impacted by blasting (Fig. 5c, e) were given green color coding

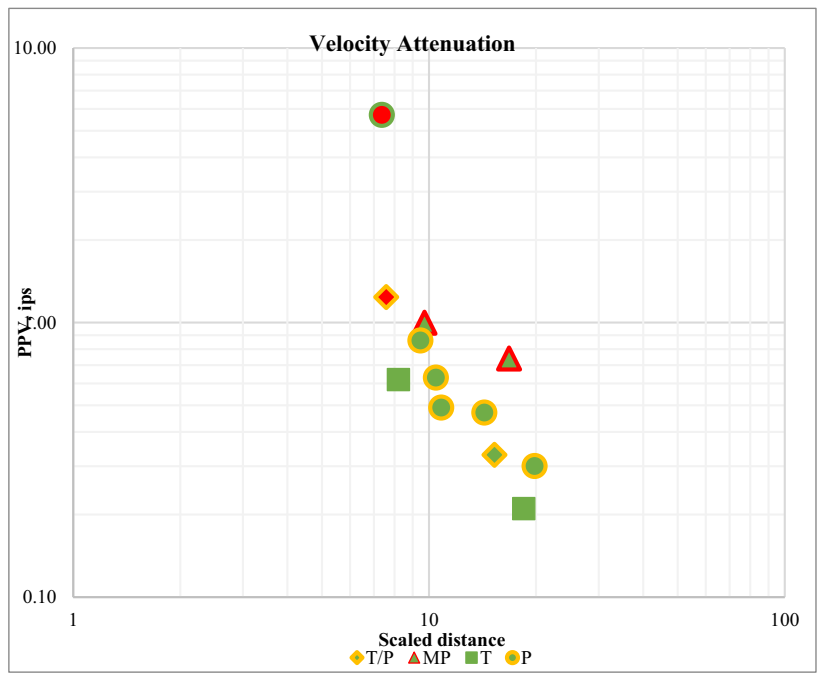

Fig. 6 Velocity attenuation curve. The outline color of each data point depicts how the value ranked with the radar criteria. The shapes depict the blast technique with circles representing production blasts, triangles representing modified production blasts, squares representing trim blasts and diamonds representing the combination trim and production blast

representing the combination trim and production blast that occurred on $7 / 24 / 19$.

Figure 6 once again proves that there is a discrepancy between the radar, blasting vibration criteria and blasting technique. This indicates that separate blasting criteria should be developed for trim/production blasts and modified production blasts. 


\subsection{Results from applicable studies}

A recent blasting study completed by Orica [2] determined that the resonant frequency ranged between 10 and $40 \mathrm{~Hz}$ in Type 4 rock. This is an extremely important result in determining an improved blast vibration criterion. Knowing the resonant frequency of Type 4 allows for accurate frequency shifting within the blasting criteria. Shifting the blast's dominant frequency is typically accomplished by changing the blast pattern timing [21]. As a note, Type 4 rock is the material of interest because all the testing discussed within this study were completed in Type 4 rock. Another reason that Type 4 rock is necessary to understand in terms of blast vibration monitoring is based on the fact that a large amount of future mining will occur in Type 4 rock. Therefore, an in-depth understanding will significantly help minimize highwall damage.

The comparison of radar to ground motion indicated PPV may have some added leniency if frequencies were kept within ideal ranges. Blast Dynamics, Inc. gives generalized recommendations that at greater than 3.5 ips beginning of damage to very weak rock will occur [24]. This is a practical level added to the criteria.

\section{Discussion}

Blast vibration criteria are necessary to understand the effects that blasting has on the mine highwall and assess the risk of damage for each blasting event. By comparing the ground vibrations in Table 1 to the radar velocities in Fig. 5 a better understanding of their relationship was achieved. However, after comparing ground vibrations, radar and blasting techniques it was evident that some improvements could be made to the blasting criteria because of the lack of correlation between these parameters. PPV and frequency do not tell the entire story concerning energy affecting the highwall. A major factor influencing the sensitive vibration areas are blasting techniques used. Within this paper, trim and modified production blasting were compared because these are techniques that are currently used at Round Mountain, and this allows for a practical application of the results.

Resonant frequency of Type 4 rock ranges between 10 and $40 \mathrm{~Hz}$, meaning that a frequency shift is needed to be outside this range to minimize rock damage. High frequency disturbance results in little to no response of the rock, meaning that the dominant frequency should be shifted to higher dominant frequencies while maintaining a low PPV $[1,21]$ if possible. Therefore, dominant frequency above $40 \mathrm{~Hz}$ is more preferable when compared to frequency under $10 \mathrm{~Hz}$. While maintaining low PPV is important, based on our results in Table 1, frequency seems to be the dominant factor. It should also be noted that a shift to higher frequency may be more important for modified production blasts because there was significant slope movement with similar frequencies when compared to the trim and production events. On 7/22/19, a large PPV of 5.70 was recorded, which showed little slope movement on the radar. Based on this, the PPV criteria can be made more lenient with the addition of a range of 1-3.5 ips being acceptable. This number is derived from Blast Dynamics [24] generalized recommendations that at greater than 3.5ips damage to very weak rock formations start to occur.

The most significant slope impacts due to vibrations occurred in Fig. $5 a$, d and f. In Fig. $5 d$, this can be attributed to the combination of trim blast and production blast, which is why it is not recommended to trim blast during the same pattern as a production blast. For Fig. $5 f$, the slope movement could be attributed to improper frequencies achieved. For Fig. 5a, the large amount of slope movement is supported by the fact that a MP blast was shot. To minimize damage in modified production blasts, it is recommended to shift the dominant frequency to higher frequencies above $40 \mathrm{~Hz}$. The findings show strong correlations that modified production blasts are acceptable near highwalls, but trim blasts should be used next to areas that are known to be extremely sensitive to vibrations. Though two vibration events are produced with a trim blast, the vibrations are reduced because the blast holes next to the highwall are less confined if free-faced properly. The trim blasts also shoot the majority of the pattern holes in a production blast prior to shooting the trim blast, which creates a buffer next to the highwall when the majority of the energy is released.

\subsection{New round mountain blasting vibration criteria}

Utilizing all of the data collected and analyzed, new blasting vibration criteria are developed for both trim and modified production blasts separately, shown in Figs. 7 and 8 , respectively.

The new criteria shown in Fig. 7 and 8 has recommendations for PPV, dominant frequency and radar velocities. The PPV ranges were made more lenient because PPV impacted the slopes less than the improper frequency ranges. With the added leniency to PPV it is recommended that if obtaining PPVs ranging from 1 to 3.5ips that the dominant frequencies should fall within the 'green' or 'Ideal' category. The recommended dominant frequency range for modified production blasts were increased to match the findings of Orica because the blasts created the most significant slope movement with no indication of any issues from the old blast criteria. The dominant frequencies for the trim blasts were 


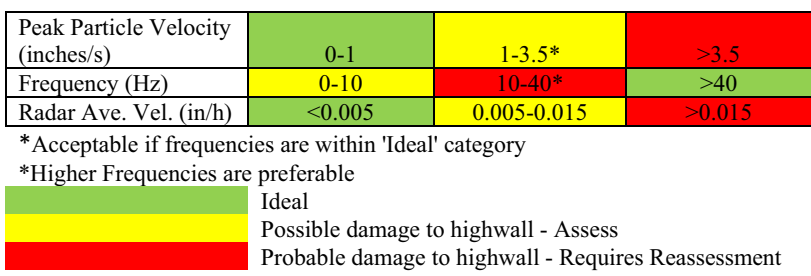

Fig. 7 New blasting criteria for modified production blasts

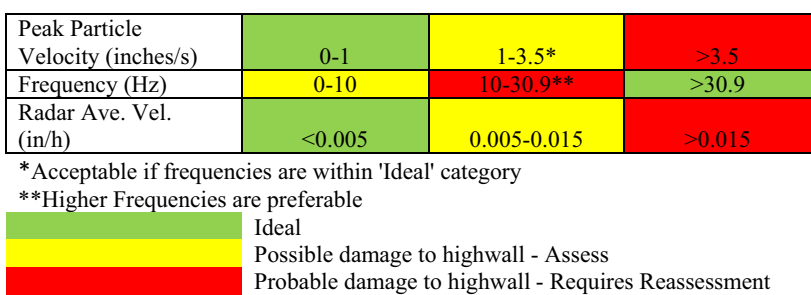

Fig. 8 New blasting criteria for trim blasting

updated as well. The value of $30.9 \mathrm{~Hz}$ is the average of all the frequencies of the blast events. The average was taken as a criteria transition value because the trim blasts appeared to be performing well at their current dominant frequencies, but keeping the 'Ideal' category at $20 \mathrm{~Hz}$ (from the old criteria) was too far under the resonant frequency of $40 \mathrm{~Hz}$. Finally, the radar criteria were developed from all events and gives criteria for both trim and modified production blasts.

While several conclusions were drawn from the data collected, it should be noted that more data would allow for an even more precise analysis to improve the blast criteria further. More blasting events and a longer-term study are needed to draw more precise conclusions about the variations between trim and production blasting as well as how other factors which impact slope stability and ground vibrations such as charge weight, blast vibration duration and stemming.

This study combines many factors to establish a new methodology to determine improved blasting criteria for Round Mountain. The purpose of developing the new criteria is to improve the highwall stability in vibration-sensitive locations along with improving the overall safety of the open pit. This work contributes to the continual effort to maintain mine work safety. Geotechnical assessments play a key roll in achieving a safe work environment and can be used to minimize highwall instability.

\section{Conclusion}

The development of new blasting criteria is a result of combining several data sets as well as recommendations from other studies. The compilation of blasting vibration data, radar and blast pattern design allowed for a practical new criteria to be developed. Improving the blasting criteria improves the safety of the mine because it restricts how unacceptable parameters are assessed. As a result, the outcome is that the highwall will be exposed to less damage with reduced effects from blasting. The less damage the highwall takes, the better. An important aspect to note is the length of time a mine can be in operation. The highwall must be continually cared for because the cost of poor design early in the mine's life will become apparent as the mine progresses.

Blast vibration data and radar are used at most open pit mines. However, a criteria combining dominant frequency, PPV and radar is not common. By using several monitoring devices, a more specific criteria was developed. The importance of incorporating the radar into the blast design criteria is that the radar measures movement of the highwall. One of the main purposes of measuring blast vibrations is to assess how the highwall is reacting to the blast. Without incorporating radar, ground motions are only being measured at points on the same bench level as the blast. Some correlations can give indications of energy entering the highwall but obtaining timely feedback from the radar is critical.

\section{Compliance with ethical standards}

Conflict of interest Authors Kyle Scalise and Karoly Kocsis declare that they have no conflicts of interest. Authors John Keefner and Thomas Ali are employees of Round Mountain Gold Corporation.

\section{References}

1. Peterson JA (2001) Blast damage mechanisms at Ekati mine. Thesis, University of Alberta, MSc

2. Yang R, Proulx R, Brown C (2019) Blast improving modeling at round mountain mine. Orica USA Inc., Technical Report

3. Zhou J, Lu W, Yan P, Chen M, Wang G (2016) Frequency-dependent attenuation of blasting vibration waves. Rock Mech Rock Eng 49:4061-4072

4. Rajmeny P, Shrimali R (2019) Use of radar technology to establish threshold values of blast vibrations. International J Rock Mech and Mining Sci 113:142-149

5. Duan B, Xia H, Yang X (2018) Impacts of bench blasting vibration on the stability of the surrounding rock. Tunn Undergr Space Technol 71:605-622

6. Carla T, Farina P, Intrieri E, Botsialas K, Casagli N (2017) On the monitoring and early-warning of brittle slope failures in hard 
rock masses: examples from and open-pit mine. Eng Geol 228:71-81

7. Hu J, Guo J, Zhou L, Zhang S, Fan K (2019) Differential groundbased radar interferometry for slope and civil structures monitoring: two case studies of landslide and bridge. Remote Sens 11(2887):1-17

8. Schaefer LN, Traglia FD, Chaussard E, Lu Z, Nolesini T (2019) Monitoring volcano slope instability with synthetic aperture radar: a review and new data from pacaya (guatemala) and stromboli (italy) volcanoes. Earth Sci Rev 192:236-257

9. Atzeni C, Barla M, Pieraccini M, Antolini F (2015) Early warning monitoring of natural and engineered slopes with ground-based synthetic-aperture radar. Rock Mech Rock Eng 48:235-246

10. Dick GJ, Eberhardt E, Cabrejo-Lievano AG, Stead D, Rose ND (2015) Development of an early-warning time-of-failure analysis methodology for open-pit mine slopes utilizing ground-based slope stability radar monitoring data. Can Geotech J 52:515-529

11. P. Saunders, J. Kabuya, A. Torres and R. Simon, 2020 "Post-blast slope stability monitoring with slope stability radar," in International Symposium on Slope Stability in Open Pit Mining and Civil Engineering, Perth

12. Shi $X$, Yang C, Zhang L, Jiang H, Liao M, Zhang L, Liu X (2019) Mapping and characterizing displacements of active loess slopes along the upstream yellow river with multi-temporal InSAR datasets. Sci Total Environ 674:200-210

13. Carla T, Farina P, Intrieri E, Ketizmen H, Casagli N (2018) Integration of ground-based radar and satellite InSAR data for the analysis of an unexpected slope failure in an open-pit mine. Eng Geol 235:39-52
14. B. P. Blair, 2015 "Wall Control Blasting," in 11 th International Symposium on Rock Fragmentation by Blasting, Syndey

15. Kinross, "Round Mountain," 2019. [Online]. Available: https:// www.kinross.com/operations/default.aspx\#americas-round mountain.

16. Kinross - Round Mountain Gold Corporation, 2008 "Technical Report on the Round Mountain Gold Mine, Nye County," Kinross, Round Mountain

17. Kinross - Round Mountain, 2019 "2019 RMGC Ground Control Management Plan," RMGC

18. White Industrial Seismology, Inc., Mini-Seis Digital Seismograph.

19. Cooley JW, Tukey JW (1965) An algorithm for the machine calculation of complex Fourier series. Math Comp 19:297-301

20. R. Telgarsky, 2013 "Dominant Frequency Extraction," ResearchGate

21. Abhinav $S$ (2017) Estimating the effects of blasting vibrations on the high-wall stability. University of Kentucky, USA

22. M. Pieraccini, 2013 "Real Beam vs. Synthetic Aperture Radar for Slope Monitoring," in Progress In Electromagnetics Research Symposium Proceedings, Stockholm

23. Reutech Mining, "MSR Modular Series," 2020. [Online]. Available: https://www.reutechmining.com/msr-modular-series/.

24. Blast Dynamics, Inc., 2006 "Vibration Control," in Predicting and Controlling Blast Vibration

Publisher's Note Springer Nature remains neutral with regard to jurisdictional claims in published maps and institutional affiliations. 